\title{
Notes and records
}

Seasonal density estimates of common large herbivores in Hwange National Park, Zimbabwe

Simon Chamaillé-Jammes ${ }^{1,2 * \dagger}$, Marion Valeix ${ }^{1,3,4 \dagger}$, Mathieu Bourgarel $^{5,6}$, Felix Murindagomo ${ }^{7}$ and Hervé Fritz ${ }^{1,3}$

${ }^{1}$ HERD CNRS/CIRAD Project, Hwange Main Camp Research, P. Bag 5776 Dete, Zimbabwe, ${ }^{2}$ Department of Botany, University of Cape Town, 7700 Rondebosch, Cape Town, South Africa, ${ }^{3}$ Wildlife Conservation Research Unit, Oxford University, Tubney House, Abingdon OX13 5QL, U.K.,

${ }^{4}$ Université de Lyon, CNRS Université Claude Bernard Lyon 1 UMR 5558, Laboratoire Biométrie et Biologie Evolutive, Bât Gregor Mendel, 43 Bd du 11 novembre 1918, 69622

Villeurbanne cedex, France, ${ }^{5}$ Centre de Coopération

Internationale en Recherche Agronomique pour le

Développement (CIRAD), UPR AGIR, Franceville, Gabon; CIRAD, UPR AGIR, Montpellier F-34398, France, ${ }^{6}$ Centre International de Recherches Médicales de Franceville, BP 769, Franceville, Gabon and ${ }^{7}$ Zimbabwe Parks and Wildlife Management Authority, Scientific Services, PO Box CY140, Causeway, Harare, Zimbabwe

\section{Introduction}

The monitoring of ecosystem processes and states is a critical step in the management of protected areas. It allows for the assessment of the success or failure of practices ranging from 'laissez-faire' to strong hands-on policies. Much effort is for instance devoted to the monitoring of wildlife abundance, particularly when associated with large ecological influence or socio-economical values (Gordon, Hester \& Festa-Bianchet, 2004). In Africa, the diversity of large herbivores represents both a major asset of protected areas and a global conservation target as a consequence of the dramatic decline of wildlife populations under other land uses. In addition to the local importance of such monitoring data, collation of data from multiple sites ultimately allows general patterns to be revealed (e.g. Fritz \& Duncan, 1994). Here, we contribute to the general

*Correspondence: E-mail: s.chamaille@yahoo.fr

'Both authors contributed equally to this work. knowledge on large African herbivores by reporting on their seasonal abundance, using road transect counts, in Hwange National Park (thereafter HNP), north-western Zimbabwe.

\section{Materials and methods}

Hwange National Park covers approximately 15,000 km² of wooded savannah with patches of grassland. Mean annual rainfall is c. $600 \mathrm{~mm}$ with the most rainfall between October and May. Between 1999 and 2005, we monitored the abundance of herbivores in four areas in the north-east of the Park where most pumped waterholes are located (Fig. 1). Main Camp and Ngamo areas are dominated by open wooded savannahs on Kalahari sands, while Sinamatella and Robins areas are dominated by Colophospermum mopane (J. Kirk ex Benth) J. Léonard woodlands on richer basalt soils interspersed with grassland vleis (Rogers, 1993). Counts were carried out in late dry season (September/October) in all areas, and in early wet (December) and early dry (May/June) seasons in Main Camp area. We used most available roads as transects (Fig. 1), which were driven at least twice per season at different time of the day with two observers. Our censuses followed the line-transect method (perpendicular distances were calculated using the angle and the direct distance between the vehicle and the animals at first detection). Although using roads as transects is questionable (Buckland et al., 2001), this often remains the only way of estimating densities over reasonably large areas and allows for comparisons with other sites. Data were analysed using Distance Sampling software (Thomas et al., 2006).

As species-specific detection functions vary essentially with vegetation structure and phenology, for each species we defined one detection function model per season in each area, pooling the data from all years available. This detection function was then applied to annual subsets of each specific season. As recommended by Buckland et al. (2001), (i) we discarded observations corresponding to the $10 \%$ largest distances. A further truncation was performed when felt necessary from the observation of the detection function; (ii) as bigger groups are more likely to be 
Fig 1 Map of Hwange National Park showing the four surveyed areas (the total length of the transects is indicated below each area). Black lines represent the transects along which herbivore abundance was monitored. Black dots represent pumped waterholes

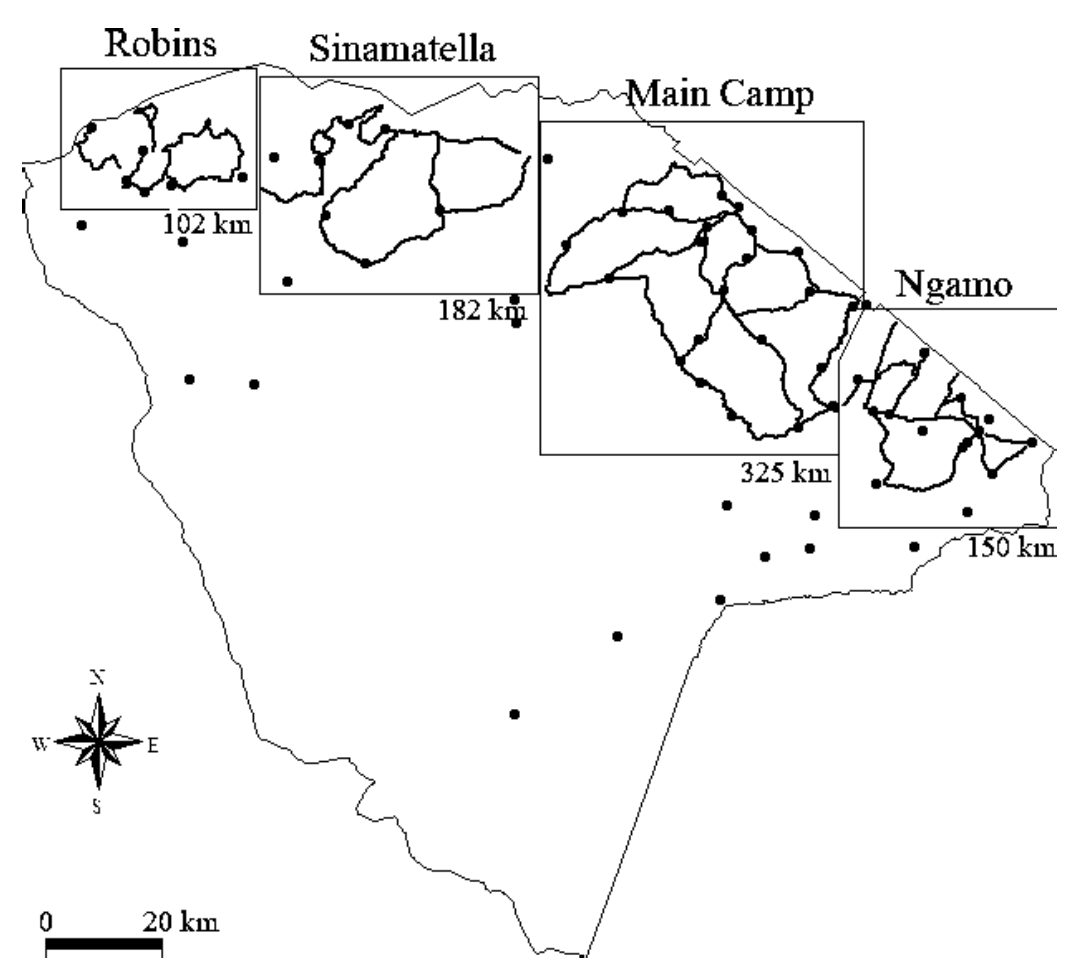

detected, we used predicted group size from size bias regression if the regression was significant (at $P<0.1$ ). If not, the mean group size was used; (iii) we studied the four key-function models (half-normal, uniform, hazard-rate and negative exponential) with cosine series expansion term. Half-normal hermite polynomial and uniform simple polynomial models were also studied; (iv) we selected the model with the smallest Akaike Information Criterion (AIC - Burnham \& Anderson, 2002). Exception was made when it was the negative exponential, known to have a low accuracy, while at least another model had a $\triangle \mathrm{AIC}<2$. The following most likely model was in such case selected; (v) we checked that the selected detection function fit the data reasonably well, i.e. that the goodness of fit chi-square test was nonsignificant $(P>0.05)$.

\section{Results and discussion}

Large herbivore communities (excluding elephants) are dominated by browsers and mixed feeders in the more wooded Robins and Sinamatella areas, and by grazers in the more open Main Camp and Ngamo areas (Table 1). The striking feature of HNP is the high abundance of elephants, reaching on average over three individuals per $\mathrm{km}^{2}$ in the late dry season in all areas (up to nine individuals per $\mathrm{km}^{2}$ in some years in the Main Camp area Fig. 2), and being one of the highest in the world (Blanc et al., 2007). On average, elephants represented between $52 \%$ and $86 \%$ of the local metabolic biomass (from Table 1). However, aerial censuses showed that elephant densities are lower in the southern part of the Park (Chamaille-Jammes, Valeix \& Fritz, 2007; and data sources therein). Local densities of elephants and other species fluctuate throughout the year with large increase in the late dry season in the Main Camp area (Fig. 2). Such fluctuations are likely to be induced by the seasonal changes in surface-water availability across the Park, with large herbivores concentrating in areas where intensive water pumping is maintained during the dry season (all studied areas - Fig. 1). Hence, densities are likely to be far higher than in the other unsurveyed areas of the park where water is rarer. This also suggests that the observed densities should not be extrapolated to other areas of the Park but likely inform on the highest dry-season herbivore densities within the Park. We have shown that elephant densities also increase during dry years in the Main Camp area when natural water availability is low in the southern part of the Park (Chamaille-Jammes et al., 2007). 


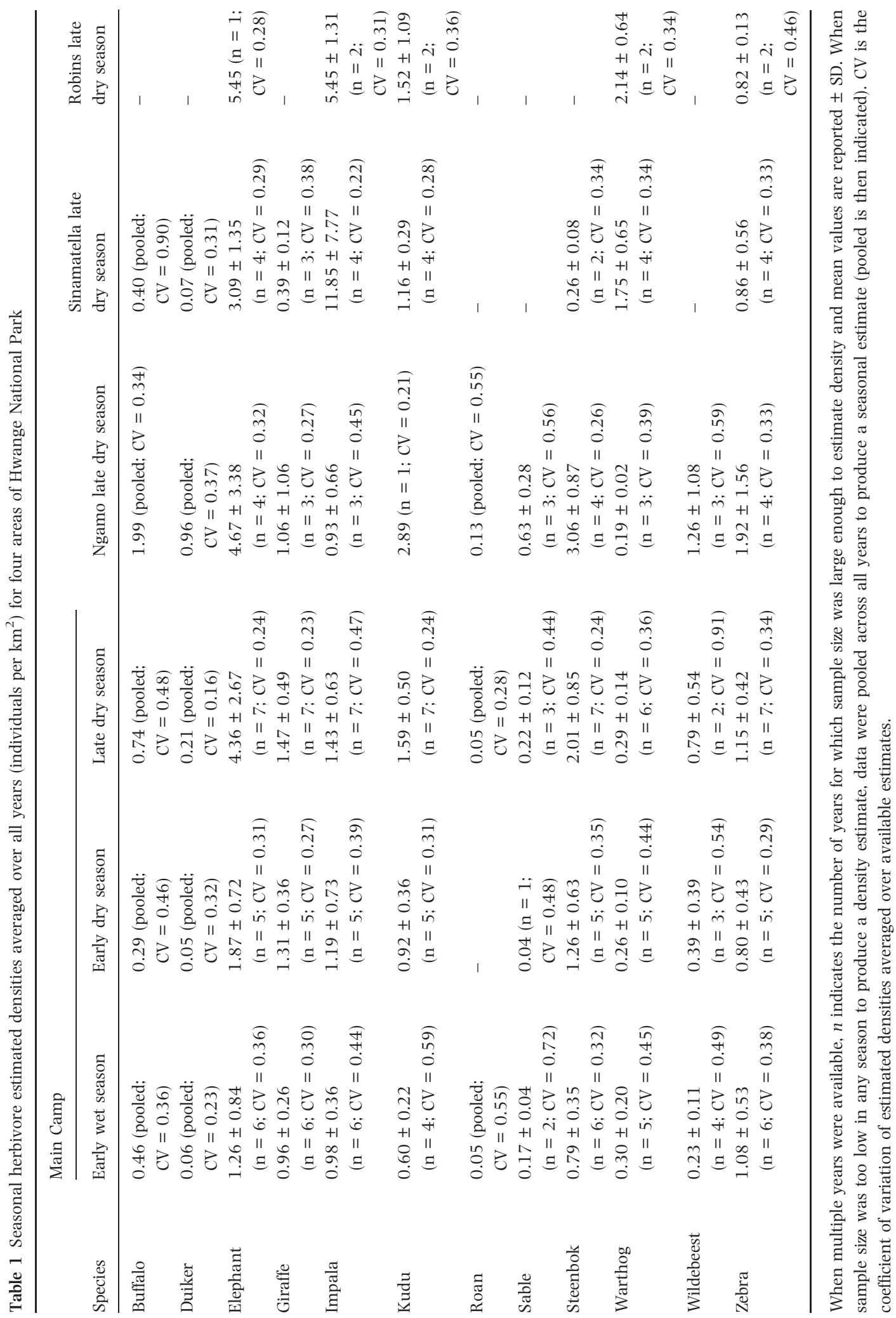




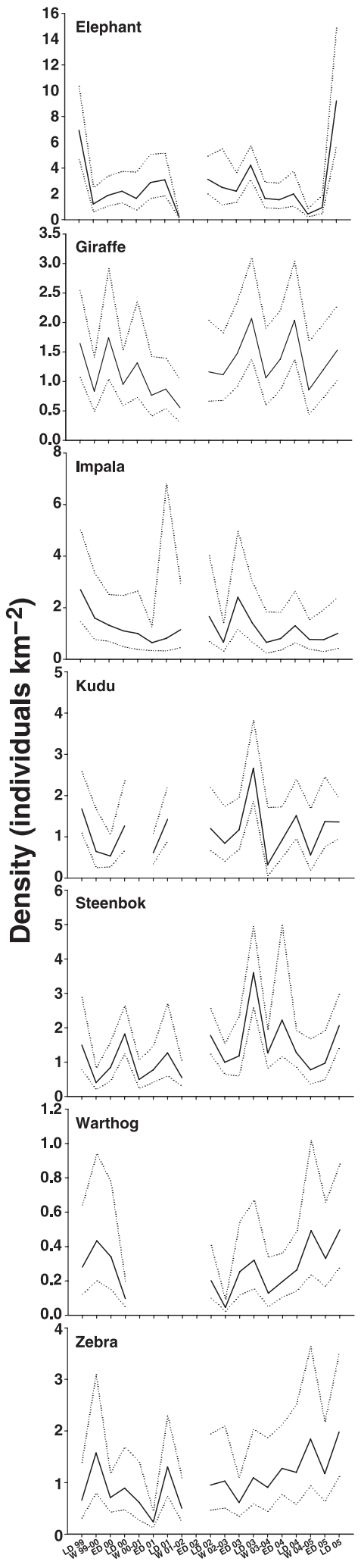

Accordingly, the relationships between large herbivore densities in the late dry season and rainfall of the previous rainy season were here all negative, although not significant $(P>0.1)$, probably because of the low sample size and high variability. Large herbivore conservation, as well as its potential influence on ecosystem processes, therefore likely result from surface-water provision in this otherwise dry land. However, there is growing evidence that overprovision of water may have detrimental consequences on the ecosystem (Gaylard, Owen-Smith \& Redfern, 2003).

Populations did not show a significant decrease during the study period, confirming that after an important decline of most species in the early 1990s attributed to either elephant increase or extended dry season or both, most herbivore populations have now stabilized at lower levels (Valeix et al., 2007).

The census data provided here highlight some important aspects of the status and functioning of HNP, and also offer baseline information for comparative studies. Such monitoring effort, however, aims at providing further insights when later used in conjunction with other environmental data and records of management practices.

\section{Acknowledgements}

The Director General of the Zimbabwe Parks and Wildlife Management Authority is acknowledged for providing the opportunity to carry out this research and for permission to publish this manuscript. This research was funded by the French 'Ministère des Affaires Etrangères', the 'Ambassade de France au Zimbabwe', the CIRAD and the CNRS. Sébastien Le Bel is acknowledged for his invaluable help in organizing this work. We also sincerely thank Dr. Hillary Madzikanda and Kwanele Kanengoni for their assistance. We thank N. Owen-Smith and an anonymous referee for their comments on the manuscript. We sincerely thank M. Britton for his help in improving the language of this manuscript. We are indebted to all the people who participated in the fieldwork, and particularly Nkululeko Hlongwane, Philani Dladla, Machengo Tinarwo, and Martin Muzamba, and to Owen Mangwana.

Fig 2 Changes in the estimated densities and 95\% confidence limits of the different common large herbivore species in Main Camp area $\left(1261 \mathrm{~km}^{2}\right)$. On the $x$-axis label, $\mathrm{W}, \mathrm{ED}$ and LD stand for wet, early dry and late dry seasons respectively, and the two last numbers indicate the year 


\section{References}

Blanc, J.J., Barnes, R.F.W., Craig, G.C., Dublin, H.T., Thouless, C.R., Douglas-Hamilton, I. \& Hart, H.T. (2007) African Elephant Status Report - An Update From the African Elephant Database. Occasional Paper of the IUCN Species, Survival Commission No. 33 IUCN, Gland.

Buckland, S.T., ANDerson, D.R., Burnham, K.P., LAaKe, J.L., Borchers, D.L. \& Thomas, L. (2001) Introduction to Distance Sampling. Estimating Abundance of Biological Populations. Oxford University Press, Oxford.

Burnham, K.P. \& ANDERson, D.R. 2002. Model Selection and Multimodel Inference: A Practical Information-Theoretical Approach. Springer-Verlag, New York, NY.

Chamaille-Jammes, S., Valeix, M. \& Fritz, H. (2007) Managing heterogeneity in elephant distribution: interactions between elephant population density and surface-water availability. J. Appl. Ecol. 44, 635-633.

Fritz, H. \& Duncan, P. (1994) On the carrying capacity for large ungulates of African savanna ecosystems. Proc. R. Soc. Lond. B 256, 77-82.

Gaylard, A., Owen-Smith, N. \& RedFern, J. (2003) Surface-water availability: implications for heterogeneity and ecosystem processes. In: The Kruger Experience. Ecology and Management of Savanna Heterogeneity (Eds J.T. Du TorT, K.H. Rogers and H.C. Biggs). Island Press, Washington, DC. pp. 171-188.

Gordon, I.J., Hester, A.J. \& Festa-Bianchet, M. (2004) The management of wild large herbivores to meet economic, conservation and environmental objectives. J. Appl. Ecol. 41, 10211031.

Rogers, C.M.L. (1993) A Woody Vegetation Survey of Hwange National Park. Department of National Parks and Wildlife Management, Harare, Zimbabwe.

Thomas, L., LaAke, J.L., Strindberg, S., Marques, F.F.C., Buckland, S.T., Borchers, D.L., Anderson, D.R., Burnham, K.P., Hedley, S.L., Pollard, J.H., Bishop, J.R.B. \& Maroues, T.A. (2006) Distance 5.0., Research Unit for Wildlife Population Assessment, University of St Andrews, UK. http://www.ruwpa.st-and.ac.uk/ distance [Accessed 12 February 2008].

Valeix, M., Fritz, H., Dubois, S., Kanengoni, K., Alleaume, S. \& Said, S. (2007) Vegetation change and herbivore abundance over a peiod of increasing elephant abundance in Hwange National Park, Zimbabwe. J. Trop. Ecol. 23, 87-93.

(Manuscript accepted 13 October 2008)

doi: 10.1111/j.1365-2028.2009.01077.x 